(c) 2020 Universidad Nacional Autónoma de México, Facultad de Estudios Superiores Zaragoza.

Este es un artículo Open Access bajo la licencia CC BY-NC-ND (http://creativecommons.org/licenses/by-nc-nd/4.0/).

TIP Revista Especializada en Ciencias Químico-Biológicas, 23: 1-14, 2020.

https://doi.org/10.22201/fesz.23958723e.2020.0.267

\title{
Levaduras adaptadas al frío: el tesoro biotecnológico de la Antártica
}

\author{
James González ${ }^{1 *}$, Lucero Romero-Aguilar ${ }^{2}$, \\ Genaro Matus-Ortega ${ }^{2}$, Juan Pablo Pardo ${ }^{2}$, \\ Alejandro Flores-Alanis ${ }^{3}$ y Claudia Segal-Kischinevzky ${ }^{1 * *}$ \\ ${ }^{1 *}$ Departamento de Biología Celular, Facultad de Ciencias. ${ }^{2}$ Departamento de \\ Bioquímica, Facultad de Medicina. ${ }^{3}$ Departamento de Microbiología y Parasitología, \\ Facultad de Medicina, Universidad Nacional Autónoma de México. Avenida \\ Universidad \# 3000, Cd. Universitaria, 04510 Coyoacán, Ciudad de México, México. \\ E-mails:*james@ciencias.unam.mx,**claudiasegal@ciencias.unam.mx
}

A la Dra. Luisa Alba Lois, Lichi, quien dedicó más de 40 años a la docencia y a la investigación en la Facultad de Ciencias de la UNAM.

\begin{abstract}
RESUMEN
Las levaduras son organismos microscópicos que están distribuidos en toda la Tierra, de modo que algunas han adaptado su metabolismo para proliferar en ambientes extremos. Las levaduras que habitan en la Antártica son un grupo de microorganismos adaptados al frío que han sido poco estudiadas. En esta revisión se describen algunas de las adaptaciones metabólicas que les permiten habitar en ambientes extremos, por ejemplo, el de la Antártica. También se abordan las consideraciones relevantes para saber si una levadura es extremófila, así como los criterios utilizados para clasificar a las levaduras por crecimiento y temperatura. Además, se explica el papel de las vías de biosíntesis de carotenoides y lípidos que están involucradas en contrarrestar a las especies reactivas de oxígeno generadas por estrés oxidante en levaduras pigmentadas y oleaginosas del género Rhodotorula. La revisión también considera aspectos de investigación básica y la importancia de las levaduras oleaginosas de la Antártica para el desarrollo de algunas aplicaciones biotecnológicas.
\end{abstract}

Palabras clave: levaduras antárticas, Rhodotorula, biosíntesis de carotenoides y lípidos, ROS.

\section{Cold-adapted yeasts: the biotechnological treasure of Antarctica}

\begin{abstract}
Yeasts are microscopic organisms that are distributed in the biomes of the whole Earth, so some yeasts species exhibit diverse metabolic adaptations that allow them to proliferate in extreme environments. Yeasts that inhabit the Antarctica represent a relatively unexplored group of cold-adapted fungi. This review describes some of the metabolic adaptations that allow yeasts to inhabit extreme environments such as those in the Antarctica. This review also addresses the relevant considerations to know whether a yeast is extremophilic, as well as the criteria used to classify by its growth and temperature. The role of carotenoid and lipid biosynthesis pathways to mitigate reactive oxygen species generated by oxidative stress in pigmented and oleaginous yeasts including the Rhodotorula genus is described. Further, this review also considers the importance of basic research in oleaginous yeast from Antarctica and the development of biotechnological applications.
\end{abstract}

Keywords: antarctic yeasts, Rhodotorula, carotenoid and lipid biosynthesis, ROS.

Artículo recibido el 09 de julio del 2020.

Artículo aceptado el 09 de noviembre del 2020. 


\section{INTRODUCCIÓN}

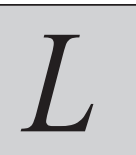

as levaduras son un grupo de microorganismos del dominio Eukarya que pertenecen al reino fungi (hongos microscópicos) y que exhiben perfiles nutricionales heterogéneos y una alta capacidad de sobrevivir en una extensa gama de hábitats (Shivaji \& Prasad, 2009). Las levaduras colonizan una gran variedad de ecosistemas y están adaptadas a diferentes temperaturas, altitudes, sustratos y ubicaciones geográficas: así, es posible encontrar levaduras en glaciares, lagos salinos, aguas ácidas, suelo, aire y profundidades marinas (Starmer \& Lachance, 2011).

En la biotecnología, las levaduras representan uno de los grupos de microorganismos más relevantes (Wolf, Breunig \& Barth, 2003; Shivaji \& Prasad, 2009). Desde hace milenios, la humanidad se ha beneficiado de estos hongos microscópicos, al emplearlos por ejemplo en la tradicional fermentación alcohólica y en la panificación. En años recientes, se ha estudiado la diversidad metabólica de las levaduras, revelando con ello numerosas posibilidades de desarrollo de aplicaciones biotecnológicas (Tabla I) (Beopoulos, Nicaud \& Gaillardin, 2011; Johnson, 2012; Buzzini \& Margesin, 2014).

Desde el siglo XVII a la actualidad, el número de nuevas especies de levaduras descritas aumenta continuamente; no obstante, se han identificado menos del $1 \%$ de todas las especies existentes, ya que se conocen aproximadamente 1,600 , lo que significa que el número esperado de éstas en la Tierra sería de alrededor de 160,000 (Lachance, 2006; Starmer \& Lachance, 2011).

En las últimas décadas, los microbiólogos han puesto gran atención a las llamadas levaduras no convencionales (Wolf et al., 2003), de las cuales las levaduras adaptadas al frío pueden considerarse un porcentaje significativo, ya que los climas fríos con temperaturas inferiores a $5{ }^{\circ} \mathrm{C}$ representan más del $80 \%$ de los ambientes del mundo (Hassan, Rafiq, Hayat, Shah \& Hasan, 2016). La mayoría de los hábitats fríos están representados por las capas de hielo y nieve árticas y antárticas, los suelos perma-congelados, los glaciares de alta montaña, el hielo marino y el agua de los océanos profundos.

En particular, la Antártica es un hábitat frío con 14 millones de $\mathrm{km}^{2}$, casi toda la superficie está cubierta de hielo y nieve (Holdgate, Ernest \& Maitland, 1977). Los ecosistemas fríos de la Antártica están asociados frecuentemente con factores abióticos limitantes, como la baja disponibilidad de agua y nutrientes, alta presión hidrostática, alta irradiación solar y estrés oxidante, lo cual hace que los hábitats antárticos sean de los más agrestes e inhóspitos de la Tierra (Claridge \& Campbell, 1977). Sin embargo, los estudios de biodiversidad y ecología microbiana han demostrado que la Antártica alberga enormes y diversos microbiomas adaptados al frío, que incluyen levaduras, hongos filamentosos, protistas y líquenes (Cameron, Kink \& David, 1970; Bej, Aislabie \& Atlas, 2010). De hecho, durante muchos años la Antártica ha sido el área geográfica preferida de los microbiólogos para estudiar la diversidad de microorganismos adaptados al frío, incluidas las levaduras (Shivaji \& Prasad, 2009).

La presente revisión describe las principales características que definen a una especie de levadura como extremófila o extremotolerante, incluida su clasificación por temperatura de supervivencia y temperatura óptima de crecimiento. Asimismo, se describen algunas de las principales estrategias de adaptación al frío en las levaduras que habitan en la Antártica como son la biosíntesis de carotenoides y de lípidos, dos biomoléculas relevantes para la biotecnología.

Tabla I. Biotecnología de levaduras: productos y/o aplicaciones.

\begin{tabular}{|l|l|}
\hline \multicolumn{1}{|c|}{$\begin{array}{c}\text { Áreas de la biotecnología } \\
\text { que utilizan levaduras }\end{array}$} & \multicolumn{1}{c|}{ Productos y/o aplicaciones } \\
\hline Fermentación tradicional & Cerveza, vino, sake, salsa de soya y otros alimentos fermentados. \\
\hline Ambiental & Biorremediación, degradación de contaminantes. \\
\hline Biocontrol & Protección de cultivos, seguridad agropecuaria, probióticos. \\
\hline Investigación en Ciencias Biomédicas & $\begin{array}{l}\text { Descubrimiento de drogas, metabolismo y resistencia a drogas, elucidación } \\
\text { de mecanismos de enfermedades. }\end{array}$ \\
\hline Investigación básica en Ciencias Biológicas & $\begin{array}{l}\text { Biología Celular y Molecular, Genómica, Genómica Funcional, Ingeniería } \\
\text { de Vías Metabólicas, Biología de Sistemas. }\end{array}$ \\
\hline Producción de proteínas & Proteínas de uso farmacéutico, enzimas, hormonas, vacunas, toxinas. \\
\hline Biocatálisis & $\begin{array}{l}\text { Farmacéuticos, intermediarios de químicos con estructuras quirales, } \\
\text { biotransformadores. }\end{array}$ \\
\hline Alimentos e ingredientes & Enzimas, saborizantes, pigmentos, aminoácidos, ácidos orgánicos. \\
\hline
\end{tabular}




\section{LEVADURAS EXTREMAS}

Las levaduras son un grupo heterogéneo de hongos microscópicos en términos de su taxonomía, fisiología y ecología, que hace difícil definir un nicho promedio "normal" o las condiciones favorables que permiten la proliferación de una levadura en términos generales. Los estudios sobre levaduras que habitan y proliferan en condiciones ambientales extremas como de temperatura, salinidad, $\mathrm{pH}$, presión, oxigenación, disponibilidad de agua, nutrientes y la presencia de sustancias tóxicas, han aumentado considerablemente en las últimas dos décadas (Buzzini \& Margesin, 2014, Raspor \& Zupan, 2006; Buzzini, Turchetti \& Yurkov, 2018). Una levadura puede considerarse como extremófila (i) si ha sido aislada en repetidas ocasiones de un hábitat extremo, (ii) si muestra capacidades fisiológicas que permiten superar el estrés ambiental del que fueron aisladas, y (iii) si tiene un crecimiento óptimo en el intervalo correspondiente a las condiciones encontradas en el hábitat extremo. Por su parte, las levaduras extremotolerantes son aquellas que crecen bajo condiciones físicas o químicas extremas sin alcanzar su crecimiento óptimo. El hecho de aislar o detectar una levadura en un ambiente extremo no significa que esta sea extremófila.

\section{TEMPERATURAS Y CLASIFICACIÓN DE LAS LEVADURAS}

La temperatura es un factor importante que determina la tasa de crecimiento de un microorganismo y permite definir una clasificación térmica con base en su crecimiento óptimo (Morita, 1975). El intervalo de temperatura de crecimiento óptimo $\left(\mathrm{TC}_{\text {opt }}\right)$ para diversas especies de levaduras mesófilas está entre los 20 y $25{ }^{\circ} \mathrm{C}$ (Figura 1) (Kurtzman, Fell, Boekhout \& Robert, 2011). La temperatura de crecimiento máxima $\left(\mathrm{TC}_{\text {máx }}\right)$ en las levaduras es de $35 \mathrm{a} 40{ }^{\circ} \mathrm{C}$, aunque estas especies son escasas y raras; cuando su temperatura de crecimiento mínima $\left(\mathrm{TC}_{\min }\right)$ es inferior a los $20^{\circ} \mathrm{C}$ se les denomina "levaduras termotolerantes" (Péter, Takashima \& Čadež, 2017). Aún así, se han identificado algunas que logran proliferar entre los 45 y $50^{\circ} \mathrm{C}$, a estas especies se les denomina "levaduras termofílicas" (Maheshwari, Bharadwaj $\&$ Bath, 2000). Mientras que a las que proliferan con éxito en ambientes fríos son conocidas como "levaduras psicrofílicas o psicrotolerantes". Las levaduras psicrofílicas tienen una $\mathrm{TC}_{\text {ópt }}$ de $15{ }^{\circ} \mathrm{C}$, una $\mathrm{TC}_{\text {máx }}$ de $20{ }^{\circ} \mathrm{C}$ y una $\mathrm{TC}_{\text {mín }}$ de $0{ }^{\circ} \mathrm{C}$. En cambio, las psicrotolerantes pueden crecer a $0{ }^{\circ} \mathrm{C}$, pero su $\mathrm{TC}_{\text {opt }}$ está entre los 20 y $30^{\circ} \mathrm{C}$ (Van Uden, 1985; Raspor \& Zupan, 2006); es decir proliferan en un intervalo de temperatura amplio, lo que permite encontrarlas en muchos hábitats fríos, ya que resisten grandes cambios de temperatura (Feller \& Gerday, 2003).

Las levaduras psicrofílicas pueden considerarse microorganismos extremófilos, ya que están adaptadas no sólo a bajas temperaturas, sino también a otros factores ambientales, como altas presiones, baja disponibilidad de nutrientes y/o agua y alta exposición a la radiación de luz

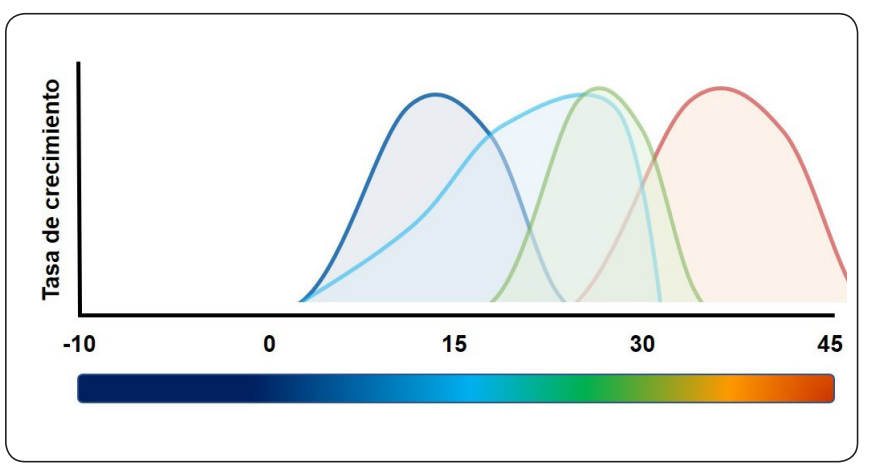

Figura 1. Clasificación de las levaduras según su crecimiento y temperatura. La curva de crecimiento de las psicrofílicas se indica en azul oscuro $\left(\mathrm{TC}_{\operatorname{mín}}=0{ }^{\circ} \mathrm{C}, \mathrm{TC}_{\text {ópt }}=15^{\circ} \mathrm{C}\right.$ y $\mathrm{TC}_{\text {máx }}=$ $20{ }^{\circ} \mathrm{C}$ ), las psicrotolerantes en azul claro $\left(\mathrm{TC}_{\text {mín }}=0{ }^{\circ} \mathrm{C}, \mathrm{TC}_{\text {ópt }}\right.$ $=20-30{ }^{\circ} \mathrm{C}$ y $\left.\mathrm{TC}_{\text {máx }} \gtrsim 30^{\circ} \mathrm{C}\right)$, las mesófilas en verde $\left(\mathrm{TC}_{\text {mín }} \gtrsim\right.$ $20^{\circ} \mathrm{C}, \mathrm{TC}_{\text {ópt }}=20-25^{\circ} \mathrm{C}, \mathrm{TC}_{\text {máx }} \gtrsim 25^{\circ} \mathrm{C}$ ) y las termotolerantes en naranja $\left(\mathrm{TC}_{\text {mín }}=20^{\circ} \mathrm{C}, \mathrm{TC}_{\text {opt }}=35-40^{\circ} \mathrm{C}\right.$ y $\left.\mathrm{TC}_{\text {máx }} \gtrsim 40^{\circ} \mathrm{C}\right)$. Elaboración personal.

ultravioleta (UV) (Friedmann, 1982; Margesin \& Miteva, 2011). En gran medida se desconocen los mecanismos moleculares y evolutivos que poseen estas levaduras para sobrevivir a los distintos tipos de estrés en hábitats extremos. Aunque la mayoría de las investigaciones que han tratado de descifrar las bases moleculares de la fisiología de las levaduras psicrofílicas se basan en estudios de levaduras modelo que no cuentan con adaptaciones al frío y/o respuestas a condiciones extremas, se sabe que bajo $0{ }^{\circ} \mathrm{C}$ algunas levaduras consumen glucosa y acumulan intermediarios del ciclo de Krebs, acetilCoA, ácido láctico, aminoácidos aromáticos, y poliamidas, sacrificando ATP y en consecuencia elevando la concentración de ADP y AMP (Inouye \& Phadtare, 2013; Tsuji, 2016). Recientemente, se describieron cambios en la metilación del DNA y por tanto, en la expresión de ciertos genes involucrados en la síntesis de proteínas y el transporte de quitina entre levaduras psicrófilas y psicrotolerantes del género Naganishia (Turchetti, Marconi, Sannino, Buzzini \& Albertini, 2020). Estos patrones diferenciales de metilación podrían ser la base para comprender los fundamentos moleculares de la adaptación de las levaduras al frío, pero se requieren realizar estudios de transcriptómica para confirmarlo.

\section{LEVADURAS PIGMENTADAS Y ESTRÉS OXIDANTE: BIOSÍNTESIS DE CAROTENOIDES}

Es probable que una de las adaptaciones más relevantes de los organismos vivos, sea el contrarrestar el daño que provoca la radiación UV. La mayoría de los organismos tienen diferentes mecanismos y compuestos para detectar la radiación UV, con el fin de prevenir un posible daño. Para contrarrestar el daño por este tipo de radiación, muchas levaduras producen compuestos fotoprotectores. Los principales grupos de compuestos fotoprotectores en levaduras adaptadas al frío son los carotenoides y las micosporinas: la presencia de 
estos fotoprotectores en diversas levaduras es un signo de su capacidad para evitar o minimizar el daño que puede causar la radiación UV (Buzzini \& Margesin, 2014).

Los carotenoides o tetraterpenoides, son pigmentos orgánicos formados por una cadena de cuarenta carbonos que se produce por la condensación sucesiva de ocho unidades de isopreno (Britton, 1995). El esqueleto básico de los carotenoides puede modificarse mediante: hidrogenación y deshidrogenación de la cadena, por reacciones de ciclación, procesos de isomerización, la incorporación de oxígeno o a través de la combinación de las modificaciones mencionadas, lo que da por resultado la síntesis de diferentes carotenoides. En este sentido, se sabe que las levaduras de los géneros Bannoa, Cryptococcus, Cystofilobasidium, Dioszegia, Erythrobasidium, Lalaria, Occutilfur, Phaffia (Xanthophyllomyces), Rhodosporidium, Rhodotorula, Saitoella, Sakaguchia, Sporidiobolus, Sporobolomyces y Taphrina producen carotenoides (Peterson, Evans, Lecce, Bell \& Etchells, 1958; Simpson, Nakayama \& Chichester, 1964; Margalith \& Meydav, 1968; Nam, Cho \& Rhee, 1988; Martelli \& da Silva, 1993; Perrier, Dubreucq \& Galzy, 1995; Madhour, Anke, Mucci, Davoli \& Weber, 2005). Los estudios pioneros se llevaron a cabo en la década de los cincuenta del siglo XX, cuando se identificó la presencia de cuatro carotenoides: torularrodina, toruleno, $\gamma$-caroteno $\mathrm{y}$ $\beta$-caroteno distribuidos en distintas proporciones en varias levaduras (Nakayama, Mackinney \& Phaff, 1954; Peterson, Bell, Etchells \& Smart Jr., 1954; Simpson et al., 1964).

Por otra parte, el papel principal de los carotenoides en las levaduras es contrarrestar las especies reactivas del oxígeno (ROS), ya que estos compuestos coloridos tienen propiedades antioxidantes (Britton, 2008). Las ROS como el anión superóxido $\left(\mathrm{O}_{2}{ }^{-}\right)$, se pueden generar en las células cuando el oxígeno $\left(\mathrm{O}_{2}\right)$ se reduce en un solo electrón en la síntesis de ATP mitocondrial durante la respiración. El $\mathrm{O}_{2}$ también se puede producir a través de la enzima nicotinamida adenina dinucleótido fosfato oxidasa, cuando la célula utiliza NADPH citosólico como donante de electrones para reducir el $\mathrm{O}_{2}$ extracelular a $\mathrm{O}_{2}{ }^{\circ}$. Otras $\operatorname{ROS}\left(\mathrm{OH}, \mathrm{OH}_{2}{ }^{\circ}, \mathrm{CO}_{3}{ }^{\circ}, \mathrm{NO}_{2}{ }^{\circ}\right.$ y $\mathrm{NO}_{3}$ ) pueden derivarse de la reacción entre $\mathrm{O}_{2}{ }^{-}$y óxido nítrico. El peróxido de hidrógeno $\left(\mathrm{H}_{2} \mathrm{O}_{2}\right)$ se puede generar a partir de $\mathrm{O}_{2}{ }^{-}$mediante la enzima superóxido dismutasa. El $\mathrm{H}_{2} \mathrm{O}_{2}$ se puede convertir en agua $\left(\mathrm{H}_{2} \mathrm{O}\right)$ mediante las siguientes enzimas: catalasa, glutatión peroxidasa y peroxirredoxina. El $\mathrm{H}_{2} \mathrm{O}_{2}$ también se puede convertir en el radical hidroxilo $\left(\mathrm{OH}^{*}\right)$ mediante la reacción de Fenton/ Haber-Weiss. Las concentraciones de las ROS fluctúan moderadamente regulando las funciones celulares, mientras que las altas concentraciones de ROS pueden provocar daño celular, generando una condición llamada estrés oxidante (Jamieson, 1998; Morano, Grant \& Moye-Rowley, 2012). Los carotenoides protegen contra las altas concentraciones de ROS y la radiación UV, debido a que varios de ellos están asociados a los lípidos de membrana, permitiendo aumentar su permeabilidad y tolerancia durante cambios de temperatura, oxidación y radiación UV (Lampila, Wallen \& Bullerman, 1985; Britton, 1995, 2008; Schroeder \& Johnson, 1995a; 1995b; Johnson \& Schroeder, 1995). La eficacia de estos pigmentos para contrarrestar el estrés oxidante está relacionada con el número de dobles enlaces conjugados en el carotenoide, los cuales determinan su estado energético de excitación. La irradiación produce en el caroteno un estado excitado de triplete cercano al del oxígeno triplete, lo que permite la transferencia de energía del oxígeno al $\beta$-caroteno $u$ otros carotenoides similares, sin que se modifique su estructura, evitando así reacciones de oxidación. La energía transferida se disipa por interacción con el solvente circundante, por lo que el carotenoide regresa a su estado fundamental (ReisMansur et al., 2019), al volver al estado desactivado puede interactuar (resonar) con el oxígeno singulete $\left(1 \mathrm{O}^{2}\right)$ activado por la energía. La interacción del $\mathrm{H}_{2} \mathrm{O}_{2}$ con los carotenoides produce un aducto químico, que da por resultado la ruptura de la estructura del polieno y la posterior pérdida del carotenoide. Respecto a la fotoprotección, los carotenoides absorben luz en el rango visible, sin embargo, hay carotenoides como el fitoeno que sólo contiene tres dobles enlaces conjugados en su estructura, mientras que el fitoflueno tiene cinco dobles enlaces, permitiendo absorber en el rango de UVB y UVA (Wilhelm \& Helmut, 2012). Además de la importancia biológica de los carotenoides, el interés por estos pigmentos aumenta debido a que representan un grupo de biomoléculas con aplicaciones biotecnológicas para la industria farmacéutica, química y alimentaria (Ausich, 1997).

La biosíntesis de los carotenoides en distintas especies de levadura se ha estudiado intensamente, uno de los géneros que se ha analizado con mayor profundidad es Rhodotorula. De hecho, se descubrió que distintas especies del género Rhodotorula ( $R$. minuta, $R$. glutinis, $R$. graminis, $R$. mucilaginosa y Rhodotorula sp. nov.) tienen perfiles similares de torularrodina, toruleno, $\gamma$-caroteno y $\beta$-caroteno(Villoutreix, 1960; Buzzini et al., 2007), confirmando que la vía de síntesis de los carotenoides es similar o está conservada en este género (Landolfo et al., 2018; Kot, Błażejak, Gientka, Kieliszek \& Bryś, 2018). Se han diseñado diferentes estrategias para incrementar la producción de carotenos en Rhodotorula spp, la que ha tenido resultados más espectaculares fue la realizada por Bhosale \& Gadre en 2001, quienes mediante mutagénesis utilizando radiación UV, lograron incrementar 15 veces la producción de carotenos totales en R. glutinis (Bhosale \& Gadre, 2001); otros autores han utilizado nitrosoguanidina, alta presión, luz UV y agentes mutagénicos y radiación UVC, logrando incrementos de 0.6 a 6 veces mayor producción de distintos carotenoides (Wang, Sun, Han \& Wu, 2007; Wang, Liu, Wang \& Lv, 2012; Nasradabi \& Razavi, 2011; Villarreal, et al., 2016. También se ha intentado elevar la producción 
utilizando inductores como luz blanca, tiamina, riboflavina, aceite de soya y jugo de tomate (Sakaki, Nakanishi, Komemushi, Namikawa \& Miki, 2001; Wang, Sha \& Wang, 2016) logrando incrementos en la producción de $\beta$-caroteno de 1-2 veces y sustratos de desecho o bajo costo como suero, salvado de arroz, residuos de plumas de aves, medio de papa, aceite de algodón y residuos de glicerol (Marova et al., 2012; Husseiny, Abdelhafez, Ali \& Sand, 2017; Taskin, Sisman, Erdal \& Kurbanoglu, 2011; Aksu \& Eren, 2005; Petrik, Marova, Haronikova, Kostovova \& Breierova, 2013), con un rendimiento de entre 1.5 a 13 veces, dependiendo de la especie de Rhodotorula y el medio. La producción de carotenoides inicia tempranamente en la vía clásica del mevalonato (MVA) hasta formar pirofosfato de isopentenilo (IPP) (Disch \&
Rohmer, 1998). La vía de biosíntesis de los carotenoides comienza con una serie de condensaciones sucesivas de unidades de isoprenoides, hasta formar el primer carotenoide incoloro, denominado fitoeno, que pierde hidrógenos hasta formar el neurosporano (color naranja) y el licopeno (color rojo). Se han descrito dos vías de ciclación independientes a partir del licopeno, que conducen a la formación de $\gamma$-caroteno y toruleno, que originan torularrodina y $\beta$-caroteno (color amarillo), respectivamente, y de este último derivan los apocarotenoides (Disch \& Rohmer, 1998; Landolfo et al., 2018; Tang, Wang, Zhang, Cai \& He, 2019). En la Figura 2 se observa la vía de MVA y la biosíntesis de carotenoides en el género Rhodotorula. En la levadura R. mucilaginosa, las enzimas fitoeno sintasa/licopeno ciclasa, fitoeno desaturasa

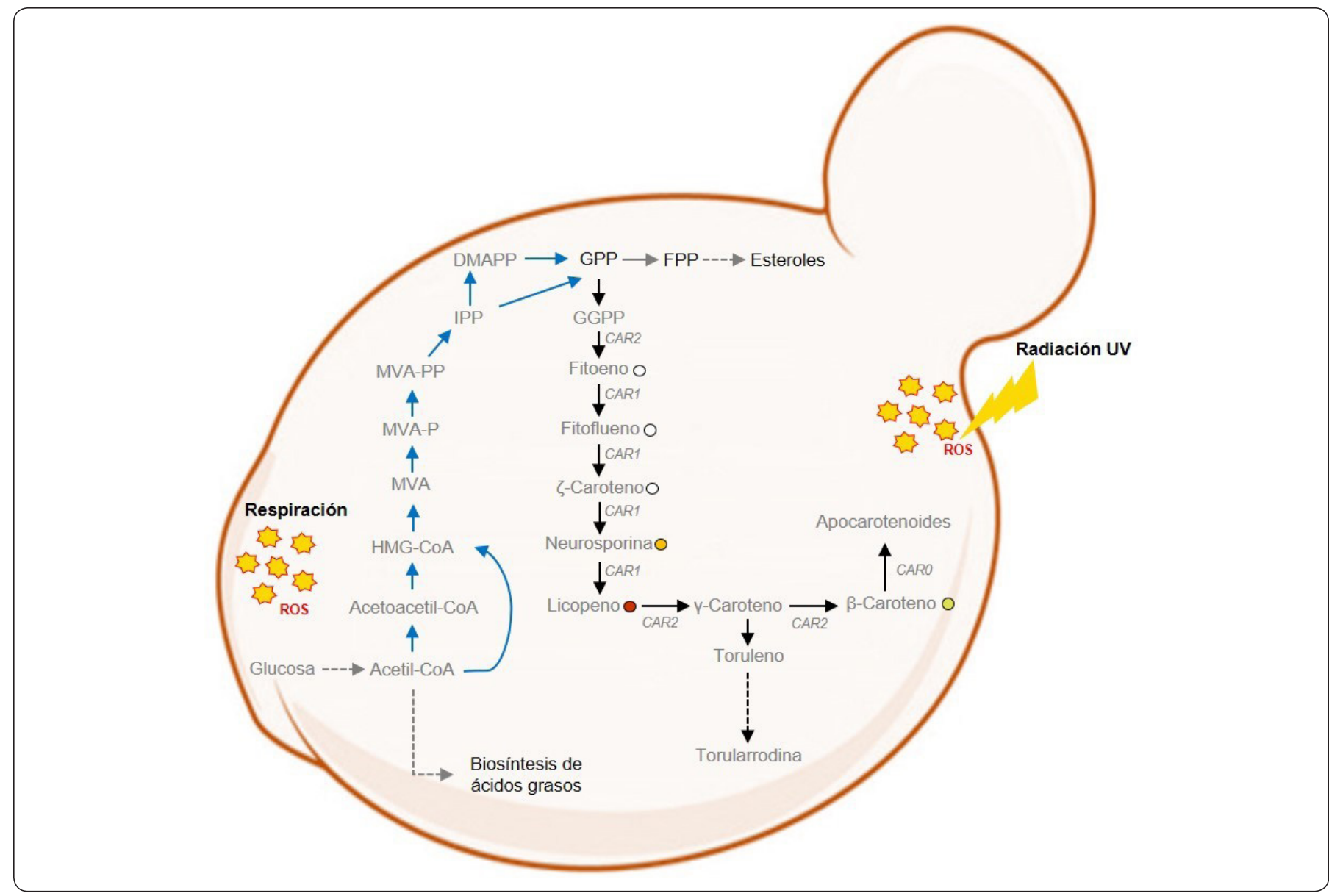

Figura 2. Esquema de la vía del mevalonato y de la biosíntesis de carotenoides en las levaduras del género Rhodotorula. Los metabolitos de ambas vías se indican en letras grises, mientras que los puntos de conexión con otras vías se señalan con flechas grises y letras negras. Las abreviaturas corresponden a las siglas en inglés de 3-hidroxi-3-metilglutaril-CoA (HMG-CoA), mevalonato (MVA), mevalonato5-fosfato (MVA-P), mevalonato-5-pirofosfato (MVA-PP), isopentenilpirofosfato (IPP), dimetilalil pirofosfato (DMAPP), geranil pirofosfato (GPP), farnesil pirofosfato (FPP) y geranilgeranil pirofosfato (GGPP). Las flechas continuas azules (vía de MVA) y negras (biosíntesis de carotenoides) representan cada paso catalítico, mientras que las flechas discontinuas indican varios pasos catalíticos. Los nombres de los principales genes que participan en la biosíntesis de carotenoides se indican con mayúsculas y cursivas (CAR2, $C A R 1$ y $C A R 0)$. El estrés oxidante puede generarse por la respiración celular, la radiación ultravioleta (UV), entre otros. La acumulación de ROS puede desencadenar un incremento en la producción de carotenoides (flechas negras) en especies del género Rhodotorula. Elaboración personal. 
y carotenoide dioxigenasa están codificadas respectivamente por los genes CAR2, CAR1 y CARO (también conocidos como crtIYB, crtI y crtS) (Landolfo et al., 2018; Tang et al., 2019). La mayoría de las enzimas involucradas en la biosíntesis de torularrodina ya han sido identificadas (Buzzini \& Margesin, 2014). Las levaduras del subfilo Pucciniomycotina (Basidiomycota) están asociadas con la producción de torularrodina, principalmente aquellas que pertenecen al género Rhodotorula que incluyen varias especies que habitan en ambientes fríos ( $R$. mucilaginosa, R. colostri, R. glutinis, entre otras) (Davoli, Mierau \& Weber, 2004; Buzzini et al., 2007).

La cantidad y perfil de cada pigmento depende de distintos factores abióticos (luz, relación de la fuente de carbono/ nitrógeno, temperatura, oxigenación, metales, iones, ROS y radiación UV) (Hayman, Yokoyama, Chichester \& Simpson, 1974; Johnson \& Lewis, 1979; Frengova, Simova \& Beshkova, 1995; Bhosale \& Bernstein, 2004, 2005; Aksu \& Eren, 2005; Frengova \& Beshkova, 2009). Asimismo, las condiciones de acidez o alcalinidad $(\mathrm{pH})$ juegan un papel importante en la acumulación de los pigmentos (Johnson \& Lewis, 1979).

\section{LEVADURAS OLEAGINOSAS Y BIODIÉSEL: BIOSÍNTESIS DE LÍPIDOS}

Las levaduras oleaginosas como materia prima alternativa tienen un uso potencial en la producción de biodiésel y constituyen una opción para sustituir la producción de combustible de primera y segunda generación, que emplean petróleo y aceite vegetal como fuente primaria, debido a que estos microorganismos pueden acumular más del $20 \%$ de su peso seco en forma de lípidos totales (Angerbauer, Siebenhofer, Mittelbach \& Guebitz, 2008; Poli et al., 2013; Sitepu et al., 2014).

La biosíntesis de lípidos se incrementa en condiciones limitadas de nitrógeno y los perfiles de ácidos grasos pueden variar entre cada especie (Tabla II) (Pan \& Rhee 1986; Czabany, Athenstaedt \& Daum, 2007; Liu \& Zhao, 2007; Zhao, Kong, Hua, Feng \& Zhao, 2008; Li, Du \& Liu, 2008; Azócar, Ciudad, Heipieper \& Navia, 2010; Ageitos, Vallejo, Veiga-Crespo \& Villa, 2011; Papanikolaou \& Aggelis, 2011). En ausencia de nitrógeno, el flujo de carbono (glucosa) se canaliza principalmente hacia la biosíntesis de triacilgliceroles (TAGs) a través de enzimas como la ATP-citrato liasa $(A C L)$, la acetil-CoA carboxilasa $(A C C 1)$, la ácido graso sintasa $1 \mathrm{y}$

Tabla II. Perfil relativo de los ácidos grasos (\%) de varias levaduras oleaginosas cultivadas en diferentes condiciones.

\begin{tabular}{|c|c|c|c|c|}
\hline Levaduras oleaginosas & C16:0 & C18:1 & C18:2 & Referencias \\
\hline Rhodotorula glutinis R4 (MM-N) & 16.78 & $57.64-61.60$ & $11.64-13.24$ & Maza et al., 2020 \\
\hline R. glacialis R15 (MM-NAG) & $23.57-26.53$ & $39.48-52.59$ & $7.41-20.11$ & Viñarta et al., 2020 \\
\hline R. glutinis R4-R48 (MM-NAG) & $21.16-27.40$ & $36.32-45.31$ & $17.66-25.24$ & \\
\hline R. glacialis R15 (MM-N) & 6.81 & 29.26 & 40.88 & Viñarta et al., 2016 \\
\hline R. glutinis R4-R48 (MM-N) & $6.93-12.38$ & $26.41-37.59$ & $31.21-57.59$ & \\
\hline R. toruloides CBS14 (MM-N) & 21.6 & 50 & 11 & $\begin{array}{l}\text { Wiebe, Koivuranta, Penttilä } \\
\text { \& Ruohonen, } 2012\end{array}$ \\
\hline R. gracilis $(\mathrm{MM}-\mathrm{N})$ & 21.8 & 56.1 & 5.1 & Choi, Ryu \& Rhee, 1982 \\
\hline Debaryomyces etchellsii (MM-N) & 18.4 & 38.8 & 27.3 & Arous et al., 2015 \\
\hline Debaryomyces hansenii Y1448 (MRG) & 23.7 & 50.1 & 2.5 & Merdinger \& Devine, 1965 \\
\hline Ustilago maydis ATCC FB2 (MM-N) & 45 & 5 & 42 & Romero-Aguilar et al., 2017 \\
\hline U. maydis ATCC FB2 (MRG) & 23 & 12 & 43 & \\
\hline U. maydis ATCC FB2 (MM+Nit) & 24 & $25-29$ & 40 & \\
\hline Cryptococcus sp. SM5S05 (MM-N) & $22.5-23$ & $56.7-57.5$ & $6.9-7.7$ & Chang et al., 2015 \\
\hline Picchia pastoris (MM-N) & 12 & 40 & 22 & Ivashov et al., 2013 \\
\hline Yarrowia lipolytica (MRG) & 22.1 & 52.5 & 11.5 & Athenstaedt et al., 2006 \\
\hline Y. lipolytica (MMAO) & 4.1 & 77 & 6.6 & \\
\hline Candida 107 (MMG-lim) & 20.4 & 39.8 & 23.7 & Gill, Hall \& Ratledge, 1977 \\
\hline
\end{tabular}


2 (FAS1 y FAS2) y la enzima málica $(M E)$ (Nielsen, 2009; Tehlivets, Scheuringer \& Kohlwein, 2007; Tang, Lee \& Chen, 2015), que luego son almacenados en los cuerpos lipídicos (Figura 3) (Ratledge, 2008; Ageitos et al., 2011; Pomraning et al., 2016; Hagiwara et al., 2016; Fakas, 2016). Los ácidos grasos de los TAGs que sintetizan las levaduras oleaginosas son similares a los ácidos grasos insaturados de los aceites vegetales que se utilizan en la elaboración de biodiésel, lo cual sustenta que los TAGs de las levaduras oleaginosas son una fuente renovable y alterna a la producción de biodiésel para las siguientes décadas (Papanikolaou, Chevalot, Komaitis, Aggelis \& Marc, 2001; Papanikolaou, Muniglia, Chevalot, Aggelis \& Marc, 2003; Papanikolaou \& Aggelis, 2011; Li et al., 2008; Beopoulos et al., 2011).
Sin embargo, aunque se han descrito más de 70 levaduras oleaginosas y de algunas de ellas se conoce su contenido y el perfil de lípidos (Kaneko, Hosohara, Tanaka \& Itoh, 1976; Meng et al., 2009; Garay et al., 2016), aún no es posible utilizar a estos microorganismos como materia prima en la producción de biodiésel a nivel industrial, ya que la obtención de biomasa es altamente costosa cuando las levaduras oleaginosas son cultivadas con glucosa como fuente de carbono (Koutinas, Chatzifragkou, Kopsahelis, Papanikolaou \& Kookos, 2014). Ante esta problemática, es importante identificar levaduras oleaginosas capaces de utilizar fuentes de carbono alternativas que promuevan la biosíntesis de lípidos y la producción de biomasa microbiana (Papanikolaou \& Aggelis., 2002; Finogenova,

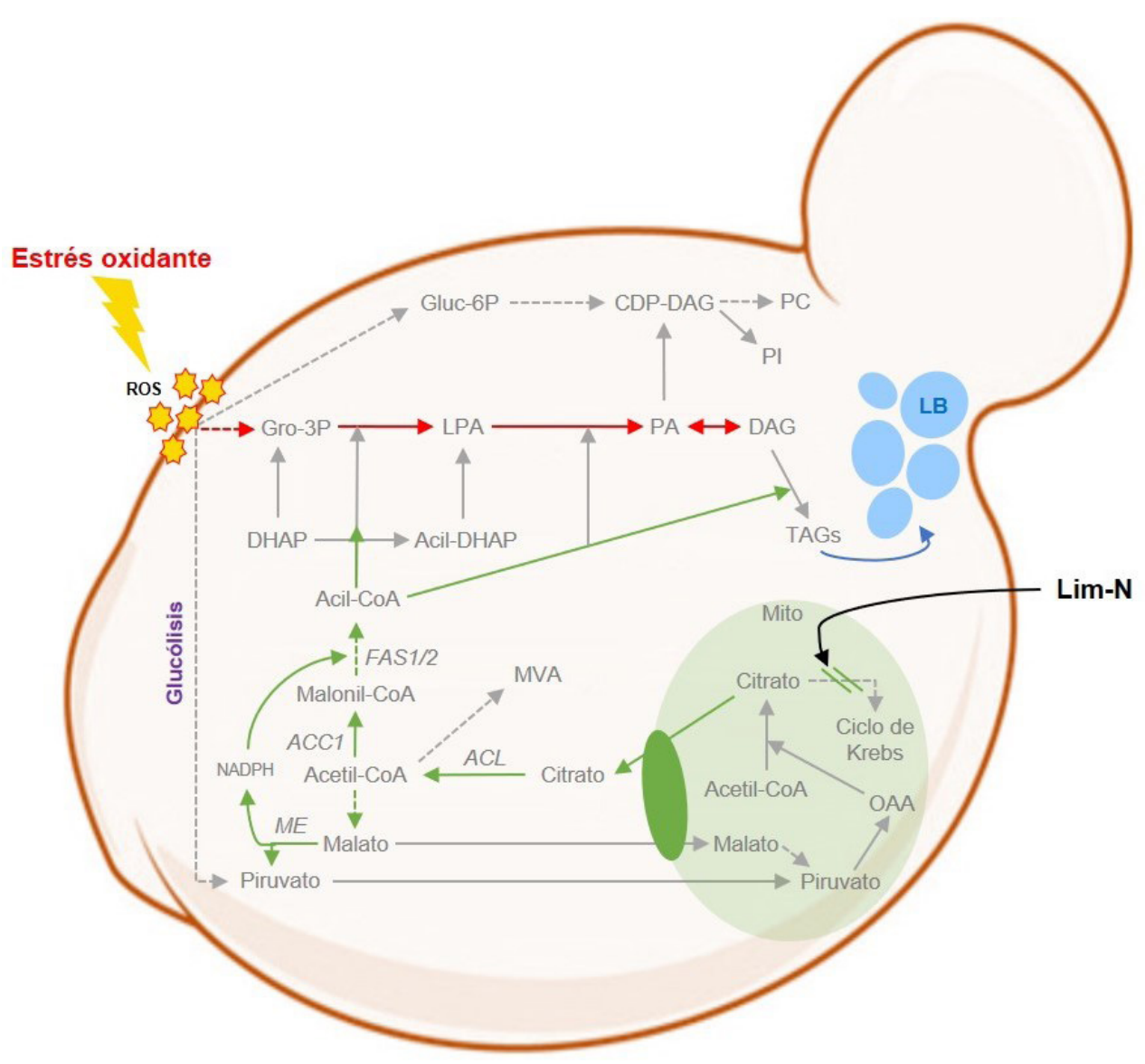

Figura 3. Esquema de la vía de biosíntesis de lípidos en las levaduras oleaginosas. Los metabolitos se señalan en letras grises. Las abreviaturas corresponden a las siglas en inglés del ácido oxaloacético (OAA), mevalonato (MVA), dihidroxiacetona fosfato (DHAP), acil-dihidroxiacetona fosfato (Acil-DHAP), glicerol-3-fosfato (Gro-3P), ácido lisofosfatídico (LPA), ácido fosfatídico (PA), diacilglicerol (DAG), triacilglicerol (TAG), glucosa-6-fosfato (Gluc-6P), CDP-diacilglicerol (CDP-DAG), fosfatidilcolina (PC) y fosfatidilinositol (PI). Las flechas discontinuas indican varios pasos catalíticos. En condiciones de estrés oxidante se generan ROS, que pueden incrementar la producción de TAGs vía Gro-3P/LPA/PA/DAG (flechas rojas). En condiciones limitadas de nitrógeno (Lim-N), el citrato de la mitocondria (Mito, verde claro) se transloca al citosol a través de la lanzadera de citrato/malato (óvalo verde oscuro), lo cual incrementa la poza de acetil-CoA y NADPH a partir del citrato que opera en el citosol, potencializando la biosíntesis de TAGs (flechas verdes). Los principales genes que participan e inician la biosíntesis de TAGs en Lim-N se indican con mayúsculas y cursivas $(A C L, A C C 1, F A S 1 / 2$ y $M E)$. Los TAGs acumulados por ambas vías se incorporan en los cuerpos lipídicos (LB) de la célula. Elaboración personal. 
Morgunov, Kamzolova \& Chernyavskaya, 2005; Taccari, Canonico, Comitini, Mannazzu \& Ciani, 2012; Xie, 2017). Los géneros más comunes entre las levaduras oleaginosas son Yarrowia, Candida, Rhodotorula, Rhodosporidium, Cryptococcus, Trichosporon y Lipomyces (Ageitos et al., 2011; Duarte, de Andrade, Ghiselli \& Maugeri, 2013; Poli et al., 2013). Por lo tanto, uno de los mayores retos en este tema es entender la fisiología y los mecanismos moleculares durante la síntesis y acumulación de TAGs de las levaduras oleaginosas con potencial biotecnológico. Por consiguiente, será indispensable que en los siguientes años se identifiquen nuevas cepas oleaginosas, capaces de asimilar fuentes de carbono renovables y económicas, así como desarrollar estrategias basadas en la evaluación de distintas condiciones de crecimiento y/o tipos de estrés que permitan incrementar la producción de TAGs y de biomasa simultáneamente y/o modificar las vías de biosíntesis mediante ingeniería genética, lo cual, en conjunto, facilitará utilizar a las levaduras como materia prima alternativa para la producción de biodiésel de manera rentable, considerando el hecho de que el metabolismo de los lípidos es influenciado notablemente por el estrés oxidante (Figura 3) (Shi et al., 2017).

\section{LA IMPORTANCIA DE LAS LEVADURAS OLEAGINOSAS DE LA ANTÁRTICA: EL CASO ESPECÍFICO DEL GÉNERO Rhodotorula}

Los hongos de la Antártica exhiben comunidades complejas que pueden sobrevivir bajo condiciones ambientales extremas, incluyendo la deshidratación, ciclos de congelación y descongelación, baja disponibilidad de nutrientes, estrés osmótico y oxidante e irradiación UV (Fell, Scorzetti, Connell \& Craig, 2006; Gonçalves, Vaz, Rosa \& Rosa, 2012). Los principales phyla fúngicos que habitan en la Antártica son Ascomycota, Basidiomycota, Zygomycota, Chytridiomycota, Glomeromycota, Oomycetes y Mycetozoa (Bridge \& Spooner, 2012). En las últimas décadas, los estudios fúngicos en la Antártica se han centrado principalmente en la identificación y el análisis de la biodiversidad de hongos que están presentes en los suelos, el hielo y los lagos. Las técnicas moleculares de secuenciación de las regiones variables [D1/D2 del gen de DNA ribosómico (rDNA) 26S, $18 \mathrm{~S}, 5.8 \mathrm{~S}$ y el gen de rDNA de las subunidades pequeñas mitocondriales, así como los espaciadores internos que se transcriben (ITS) y los fragmentos de restricción de longitud polimórfica (RFLP)] han contribuido enormemente tanto en la identificación de nuevas especies, así como a verificar las que fueron erróneamente clasificadas durante el pasado (Fell, Boekhout, Fonseca, Scorzetti \& Statzell-Tallman, 2000; Kurtzman et al., 2011). Los estudios tradicionales de secuenciación de las regiones variables y la secuenciación de nueva generación que incluye el análisis de metagenomas, han permitido identificar nuevas especies de levaduras en distintos hábitats terrestres de la Antártica (Carrasco et al., 2012;
Baeza, Barahona, Alcaíno \& Cifuentes, 2017). Actualmente, la academia y la industria tienen gran interés en el estudio de las levaduras de la Antártica, ya que representan un enorme potencial biotecnológico debido a su capacidad distintiva de crecer y metabolizar a bajas temperaturas. La adaptabilidad fisiológica de estas levaduras ha permitido la producción de pigmentos, lípidos, metabolitos secundarios, enzimas activas en frío, proteínas de choque térmico, membranas celulares con alto grado de ácidos grasos insaturados, etc (Buzzini \& Margesin, 2014; Alcaíno, Cifuentes \& Baeza, 2015; Barahona et al., 2016; Buzzini et al., 2018).

Se sabe que la temperatura define el grado de fluidez de la membrana celular mediante cambios en la concentración de ácidos grasos (Rilfors \& Lindblom, 2002). Al aumentar la temperatura, los organismos termófilos ajustan la concentración de ácidos grasos saturados logrando mantener una fluidez óptima (Arthur \& Watson, 1976). Sin embargo, para prosperar con éxito en hábitats con bajas temperaturas, los organismos psicrofílicos tienen adaptaciones estructurales y funcionales, entre ellas destacan la producción y acumulación de ácidos grasos poliinsaturados (Buzzini \& Margesin, 2014).

La Antártica posee una fuente importante de levaduras oleaginosas, con adaptaciones que permiten acumular cantidades considerables de lípidos con interés biotecnológico a temperaturas entre los 15 y $25{ }^{\circ} \mathrm{C}$ (Rossi et al., 2009; Amaretti et al., 2010; Viñarta et al., 2016). Recientemente, se reportó que algunas levaduras aisladas del suelo de la Antártica contienen un alto porcentaje de ácido linoleico (omega-6) y oleico (omega-9), sugiriendo que estos microorganismos podrían tener un uso potencial en la producción de lípidos con valor comercial (Villarreal et al., 2018; Maza, Viñarta, Su, Guillamón \& Aybar, 2020). Entre las levaduras oleaginosas de la Antártica, destacan las especies pertenecientes al género Rhodotorula, las cuales son excelentes productoras de ácidos grasos en forma de TAGs (Tabla II). De hecho, ya se ha considerado que los TAGs de algunas cepas de Rhodotorula podrían resultar de gran utilidad como materia prima alternativa para la producción de biodiésel (Viñarta et al., 2016; Viñarta, Angelicola, Nieuwenhove, Aybar \& de Figueroa, 2020; Maza et al., 2020). A pesar de que el género Rhodotorula se encuentra en varios ambientes, existen pocos estudios comparativos entre especies psicrofílicas y/o psicrotolerantes provenientes de distintos hábitats. Además, son escasos los estudios enfocados a investigar la capacidad de acumulación de ácidos grasos entre especies de Rhodotorula aisladas de la Antártica. Asimismo, se desconocen las redes de genes y se sabe poco sobre las vías que participan en el metabolismo de lípidos de novo, debido a que la mayoría de los estudios están basados en la levadura convencional Saccharomyces cerevisiae, la cual no cuenta con adaptaciones de condiciones de hábitats fríos y extremos. 
En general, algunas levaduras antárticas oleaginosas del género Rhodotorula, pueden considerarse como fábricas celulares de lípidos con potencial biotecnológico, pero se requieren estudios más enfocados al metabolismo de las levaduras adaptadas al frío, que conduzcan a la comprensión de las vías y los mecanismos moleculares de la biosíntesis y acumulación de lípidos. Considerando todo lo anterior, las levaduras antárticas oleaginosas del género Rhodotorula, representan un buen modelo de estudio para aportar nuevo conocimiento y desarrollar novedosas aplicaciones con interés biotecnológico, como la producción de biodiésel.

\section{Conclusiones}

Los ecosistemas agrestes y fríos de la Antártica albergan una gran diversidad de levaduras, entre ellas destacan las psicrofílicas y las psicrotolerantes. Las levaduras antárticas tienen vías metabólicas de biosíntesis de carotenoides y lípidos, que les permiten adaptarse a condiciones extremas como a la exposición de altas concentraciones de ROS y un alto índice de radiación UV. Los pigmentos y lípidos producidos por algunas levaduras antárticas del género Rhodotorula son valiosos para la industria farmacéutica, química, alimentaria y energética, por ello se les considera el tesoro biotecnológico de la Antártica.

\section{Agradecimientos}

Agradecemos al Programa de Apoyo a Proyectos de Investigación e Innovación Tecnológica (PAPIIT/DGAPA/ UNAM IA208820 e IN225320) por otorgar financiamiento para desarrollar nuestra investigación.

\section{REFERENCIAS}

Ageitos, J., Vallejo, J., Veiga-Crespo, P. \& Villa, T. (2011). Oily yeasts as oleaginous cell factories. Applied Microbiology and Biotechnology, 90(4), 1219-1227. DOI: 10.1007/ s00253-011-3200-Z

Aksu, Z. \& Eren, A. (2005). Carotenoids production by the yeast Rhodotorula mucilaginosa: Use of agricultural wastes as a carbon source. Process Biochemistry, 40(9), 2985-2991. DOI: 10.1016/j.procbio.2005.01.011

Alcaíno, J., Cifuentes, V. \& Baeza, M. (2015). Physiological adaptations of yeasts living in cold environments and their potential applications. World Journal of Microbiology and Biotechnology, 31(10), 1467-1473. DOI: 10.1007/ s11274-015-1900-8

Amaretti, A., Raimondi, S., Sala, M., Roncaglia, L., De Lucia, M., Leonardi, A. \& Rossi, M. (2010). Single cell oils of the cold-adapted oleaginous yeast Rhodotorula glacialis DBVPG 4785. Microbial Cell Factories, 9(1). DOI: 10.1186/1475-2859-9-73

Angerbauer, C., Siebenhofer, M., Mittelbach, M. \& Guebitz, G. (2008). Conversion of sewage sludge into lipids by Lipomyces starkeyi for biodiesel production. Bioresource Technology, 99(8), 3051-3056. DOI: 10.1016/j.biortech.2007.06.045

Arous, F., Triantaphyllidou, I., Mechichi, T., Azabou, S., Nasri, M. \& Aggelis, G. (2015). Lipid accumulation in the new oleaginous yeast Debaryomyces etchellsii correlates with ascosporogenesis. Biomass and Bioenergy, 80, 307315. DOI: 10.1016/j.biombioe.2015.06.019

Arthur, H. \& Watson, K. (1976). Thermal adaptation in yeast: growth temperatures, membrane lipid, and cytochrome composition of psychrophilic, mesophilic, and thermophilic yeasts. Journal of Bacteriology, 128(1), 5668. Retrieved from https://jb.asm.org/content/128/1/56

Athenstaedt, K., Jolivet, P., Boulard, C., Zivy, M., Negroni, L., Nicaud, J. \& Chardot, T. (2006). Lipid particle composition of the yeast Yarrowia lipolytica depends on the carbon source. Proteomics, 6(5), 1450-1459. DOI: 10.1002/pmic. 200500339

Ausich, R. (1997). Commercial opportunities for carotenoid production by biotechnology. Pure and Applied Chemistry, 69(10), 2169-2174. DOI: 10.1351/pac199769102169

Azócar, L., Ciudad, G., Heipieper, H. \& Navia, R. (2010). Biotechnological processes for biodiesel production using alternative oils. Applied Microbiology and Biotechnology, 88(3), 621-636. DOI: 10.1007/s00253-010-2804-z

Baeza, M., Barahona, S., Alcaíno, J. \& Cifuentes, V. (2017). Amplicon-Metagenomic Analysis of Fungi from Antarctic Terrestrial Habitats. Frontiers in Microbiology, 8. DOI: 10.3389/fmicb.2017.02235

Barahona, S., Yuivar, Y., Socias, G., Alcaíno, J., Cifuentes, V. \& Baeza, M. (2016). Identification and characterization of yeasts isolated from sedimentary rocks of Union Glacier at the Antarctica. Extremophiles, 20(4), 479-491. DOI: 10.1007/s00792-016-0838-6

Bej A. K., Aislabie J. \& Atlas, R. M. (eds) (2010). "Microbiology of Antarctic terrestrial soils and rocks", in Polar Microbiology: The Ecology, Biodiversity and Bioremediation Potential of Microorganisms in Extremely Cold Environments. (Boca Raton, FL: CRC Press), 1-29.

Beopoulos, A., Nicaud, J. \& Gaillardin, C. (2011). An overview of lipid metabolism in yeasts and its impact on biotechnological processes. Applied Microbiology and Biotechnology, 90(4), 1193-1206. DOI: 10.1007/s00253011-3212-8

Bhosale, P. \& Bernstein, P. (2004). $\beta$-Carotene production by Flavobacterium multivorum in the presence of inorganic salts and urea. Journal of Industrial Microbiology \& Biotechnology, 31(12), 565-571. DOI: 10.1007/s10295004-0187-9

Bhosale, P. \& Bernstein, P. (2005). Microbial xanthophylls. Applied Microbiology and Biotechnology, 68(4), 445455. DOI: $10.1007 / \mathrm{s} 00253-005-0032-8$

Bhosale, P. \& Gadre, R.V. (2001). Production of $\beta$-carotene by a Rhodotorula glutinis mutant in sea water medium. Bioresource Technology, 76(1), 53-55. DOI: 10.1016/ S0960-8524(00)00075-4 
Bridge, P. \& Spooner, B. (2012). Non-lichenized Antarctic fungi: transient visitors or members of a cryptic ecosystem? Fungal Ecology, 5(4), 381-394. DOI: 10.1016/j.funeco.2012.01.007

Britton, G. (1995). Structure and properties of carotenoids in relation to function. The FASEB Journal, 9(15), 15511558. DOI: 10.1096/fasebj.9.15.8529834

Britton, G. (2008). Functions of Intact Carotenoids. Carotenoids, 189-212. DOI: 10.1007/978-3-7643-7499-0_10

Buzzini, P. \& Margesin, R. (2014). Cold-adapted Yeasts. Biodiversity, Adaptation Strategies and Biotechnological Significance: A lesson from the cold and a challenge for the XXI century. In Buzzini P, Margesin R (eds) Coldadapted yeasts. Springer, Berlin, Heidelberg, pp 3-22.

Buzzini, P., Innocenti, M., Turchetti, B., Libkind, D., van Broock, M. \& Mulinacci, N. (2007). Carotenoid profiles of yeasts belonging to the genera Rhodotorula, Rhodosporidium, Sporobolomyces, and Sporidiobolus. Canadian Journal of Microbiology, 53(8), 1024-1031. DOI: 10.1139/w07-068

Buzzini, P., Turchetti, B. \& Yurkov, A. (2018). Extremophilic yeasts: the toughest yeasts around? Yeast, 35(8), 487-497. DOI: $10.1002 /$ yea.3314

Cameron, R., Kink, J. \& David, C. (1970). Microbiology, ecology and microclimatology of soil sites in dry valleys of southern Victoria Land, Antarctica. Antarctic Ecology, 702-716. Microbiology, ecology and microclimatology of soil sites in Dry Valleys of southern Victoria land, Antarctica.

Carrasco, M., Rozas, J., Barahona, S., Alcaíno, J., Cifuentes, V. \& Baeza, M. (2012). Diversity and extracellular enzymatic activities of yeasts isolated from King George Island, the sub-Antarctic region. BMC Microbiology, 12(1), 251. DOI: 10.1186/1471-2180-12-251

Chang, Y., Chang, K., Lee, C., Hsu, C., Huang, C. \& Jang, H. (2015). Microbial lipid production by oleaginous yeast Cryptococcus sp. in the batch cultures using corncob hydrolysate as carbon source. Biomass and Bioenergy, 72, 95-103. DOI: 10.1016/j.biombioe.2014.11.012

Choi, S., Ryu, D. \& Rhee, J. (1982). Production of microbial lipid: Effects of growth rate and oxygen on lipid synthesis and fatty acid composition of Rhodotorula gracilis. Biotechnology and Bioengineering, 24(5), 1165-1172. DOI: $10.1002 /$ bit.260240513

Claridge, G. G. \& Campbell, I. B. (1977). The salts in Antarctic soils, their distribution and relationship to soil processes. Soil Science, 377-384. DOI: 10.1097/00010694-197706000 $-00006$

Czabany, T., Athenstaedt, K. \& Daum, G. (2007). Synthesis, storage and degradation of neutral lipids in yeast. Biochimica et Biophysica Acta (BBA) - Molecular and Cell Biology of Lipids, 1771(3), 299-309. DOI: 10.1016/j. bbalip.2006.07.001

Davoli, P., Mierau, V. \& Weber, R. (2004). Carotenoids and Fatty Acids in Red Yeasts Sporobolomyces roseus and Rhodotorula glutinis. Applied Biochemistry and Microbiology, 40(4), 392-397. DOI: 10.1023/b:abim.0000033917.57177.f2

Disch, A. \& Rohmer, M. (1998). On the absence of the glyceraldehyde 3-phosphate/pyruvate pathway for isoprenoid biosynthesis in fungi and yeasts. FEMS Microbiology Letters, 168(2), 201-208. DOI: 10.1111/ j.1574-6968.1998.tb13274.x

Duarte, S., de Andrade, C., Ghiselli, G. \& Maugeri, F. (2013). Exploration of Brazilian biodiversity and selection of a new oleaginous yeast strain cultivated in raw glycerol. Bioresource Technology, 138, 377-381. DOI: 10.1016/j. biortech.2013.04.004

Fakas, S. (2016). Lipid biosynthesis in yeasts: A comparison of the lipid biosynthetic pathway between the model nonoleaginous yeast Saccharomyces cerevisiae and the model oleaginous yeast Yarrowia lipolytica. Engineering in Life Sciences, 17(3), 292-302. DOI: 10.1002/ elsc. 201600040

Fell, J., Boekhout, T., Fonseca, A., Scorzetti, G. \& StatzellTallman, A. (2000). Biodiversity and systematics of basidiomycetous yeasts as determined by large-subunit rDNA D1/D2 domain sequence analysis. International Journal of Systematic and Evolutionary Microbiology, 50(3), 1351-1371. DOI: 10.1099/00207713-50-3-1351

Fell, J., Scorzetti, G., Connell, L. \& Craig, S. (2006). Biodiversity of micro-eukaryotes in Antarctic Dry Valley soils with $<5 \%$ soil moisture. Soil Biology and Biochemistry, 38(10), 3107-3119. DOI: 10.1016/j. soilbio.2006.01.014

Feller, G. \& Gerday, C. (2003). Psychrophilic enzymes: hot topics in cold adaptation. Nature Reviews Microbiology, 1(3), 200-208. DOI: 10.1038/nrmicro773

Finogenova, T., Morgunov, I., Kamzolova, S. \& Chernyavskaya, O. (2005). Organic Acid Production by the Yeast Yarrowia lipolytica: A Review of Prospects. Applied Biochemistry and Microbiology, 41(5), 418-425. DOI: $10.1007 /$ s10438-005-0076-7

Frengova, G. \& Beshkova, D. (2009). Carotenoids from Rhodotorula and Phaffia: yeasts of biotechnological importance. Journal of Industrial Microbiology \& Biotechnology, 36(2), 163-180. DOI: 10.1007/s10295008-0492-9

Frengova, G., Simova, E. \& Beshkova, D. (1995). Effect of temperature changes on the production of yeast pigments co-cultivated with lacto-acid bacteria in whey ultrafiltrate. Biotechnology Letters, 17(9), 1001-1006. DOI: 10.1007/ bf00127443

Friedmann, E. (1982). Endolithic Microorganisms in the Antarctic Cold Desert. Science, 215(4536), 1045-1053. DOI: $10.1126 /$ science.215.4536.1045

Garay, L., Sitepu, I., Cajka, T., Chandra, I., Shi, S., Lin, T., German, J. B., Fiehn O. \& Boundy-Milss, K. L. (2016). 
Eighteen new oleaginous yeast species. Journal of Industrial Microbiology \& Biotechnology, 43(7), 887900. DOI: 10.1007/s10295-016-1765-3

Gill, C., Hall, M. \& Ratledge, C. (1977). Lipid accumulation in an oleaginous yeast (Candida 107) growing on glucose in single-stage continuous culture. Applied and Environmental Microbiology, 33(2), 231-239. Retrieved from https://aem.asm.org/content/33/2/231.long

Gonçalves, V., Vaz, A., Rosa, C. \& Rosa, L. (2012). Diversity and distribution of fungal communities in lakes of Antarctica. FEMS Microbiology Ecology, 82(2), 459471. DOI: 10.1111/j.1574-6941.2012.01424.x

Hagiwara, K., Okura, M., Sumikawa, Y., Hida, T., Kuno, A., Horio, Y. \& Yamashita, T. (2016). Biochemical effects of the flavanol-rich lychee fruit extract on the melanin biosynthesis and reactive oxygen species. The Journal of Dermatology, 43(10), 1174-1183. DOI: 10.1111/13468138.13326

Hassan, N., Rafiq, M., Hayat, M., Shah, A. \& Hasan, F. (2016). Psychrophilic and psychrotrophic fungi: a comprehensive review. Reviews in Environmental Science and Bio/ Technology, 15(2), 147-172. DOI: 10.1007/s11157-0169395-9

Hayman, E., Yokoyama, H., Chichester, C. \& Simpson, K. (1974). Carotenoid Biosynthesis in Rhodotorula glutinis. Journal of Bacteriology, 120(3), 1339-1343. Retrieved from https://jb.asm.org/content/120/3/1339.long

Holdgate, M. W., Ernest, F. V. \& Maitland, L.R. (1997). Life sciences - Terrestrial ecosystems in the Antarctic. Philosophical Transactions of the Royal Society of London. B, Biological Sciences. Retrieved from https:// doi.org/10.1098/rstb.1977.0068

Husseiny, S., Abdelhafez, A., Ali, A. \& Sand, H. (2017). Optimization of $\beta$-Carotene Production from Rhodotorula glutinis ATCC 4054 Growing on Agro-industrial Substrate Using Plackett-Burman Design. Proceedings of The National Academy of Sciences, India Section B: Biological Sciences, 88(4), 1637-1646. DOI: 10.1007/ s40011-017-0908-2

Ivashov, V., Grillitsch, K., Koefeler, H., Leitner, E., Baeumlisberger, D., Karas, M. \& Daum, G. (2013). Lipidome and proteome of lipid droplets from the methylotrophic yeast Pichia pastoris. Biochimica et Biophysica Acta (BBA) - Molecular and Cell Biology of Lipids, 1831(2), 282-290. DOI: 10.1016/j. bbalip.2012.09.017

Jamieson, D. (1998). Oxidative stress responses of the yeast Saccharomyces cerevisiae. Yeast, 14(16), 1511-1527. DOI: 10.1002/(sici)1097-0061(199812)14:16<1511::aidyea356>3.0.co;2-s

Johnson, E. (2012). Biotechnology of non-Saccharomyces yeasts - the ascomycetes. Applied Microbiology and Biotechnology, 97(2), 503-517. DOI: 10.1007/s00253012-4497-y
Johnson, E. \& Lewis, M. (1979). Astaxanthin Formation by the Yeast Phaffia rhodozyma. Journal of General Microbiology, 115(1), 173-183. DOI: 10.1099/00221287115-1-173

Johnson, E. \& Schroeder, W. (1995). Microbial carotenoids. In: Downstream Processing Biosurfactants Carotenoids. Advances in Biochemical Engineering/Biotechnology, 53, 119-178 Springer, Berlin, Heidelberg. https://doi. org/10.1007/BFb0102327

Kaneko, H., Hosohara, M., Tanaka, M. \& Itoh, T. (1976). Lipid composition of 30 species of yeast. Lipids, 11(12), 837-844. DOI: $10.1007 /$ bf02532989

Kot, A., Błażejak, S., Gientka, I., Kieliszek, M. \& Bryś, J. (2018). Torulene and torularhodin: "new" fungal carotenoids for industry? Microbial Cell Factories, 17(1). DOI: $10.1186 / \mathrm{s} 12934-018-0893-\mathrm{z}$

Koutinas, A., Chatzifragkou, A., Kopsahelis, N., Papanikolaou, S. \& Kookos, I. (2014). Design and techno-economic evaluation of microbial oil production as a renewable resource for biodiesel and oleochemical production. Fuel, 116, 566-577. DOI: 10.1016/j.fuel.2013.08.045

Kurtzman, C., Fell, J., Boekhout, T. \& Robert, V. (2011). Methods for Isolation, Phenotypic Characterization and Maintenance of Yeasts. Chapter 7. In: The Yeasts, 87-110. DOI: 10.1016/B978-0-444-52149-1.00007-0

Lachance, M. (2006). Yeast Biodiversity: How Many and How Much? In: Péter, G. \& Rosa, C. (eds) Biodiversity and Ecophysiology of Yeasts. The Yeast Handbook, 1-9. Springer, Berlin, Heidelberg. DOI: 10.1007/3-54030985-3 1

Lampila, L., Wallen, S. \& Bullerman, L. (1985). A review of factors affecting biosynthesis of carotenoids by the order Mucorales. Mycopathologia, 90(2), 65-80. DOI: 10.1007/ bf00436853

Landolfo, S., Ianiri, G., Camiolo, S., Porceddu, A., Mulas, G. Chessa, R., Zara, G. \& Manazzu, G. (2018). CAR gene cluster and transcript levels of carotenogenic genes in Rhodotorula mucilaginosa. Microbiology, 164(1), 78-87. DOI: $10.1099 /$ mic. 0.000588

Li, Q., Du, W. \& Liu, D. (2008). Perspectives of microbial oils for biodiesel production. Applied Microbiology and Biotechnology, 80(5), 749-756. DOI: 10.1007/s00253008-1625-9

Liu, B. \& Zhao, Z. (2007). Biodiesel production by direct methanolysis of oleaginous microbial biomass. Journal of Chemical Technology \& Biotechnology, 82(8), 775780. DOI: $10.1002 /$ jctb. 1744

Madhour, A., Anke, H., Mucci, A., Davoli, P. \& Weber, R. (2005). Biosynthesis of the xanthophyll plectaniaxanthin as a stress response in the red yeast Dioszegia (Tremellales, Heterobasidiomycetes, Fungi). Phytochemistry, 66(22), 2617-2626. DOI: 10.1016/j.phytochem.2005.09.010

Maheshwari, R., Bharadwaj, G. \& Bhat, M. (2000). Thermophilic Fungi: Their Physiology and Enzymes. 
Microbiology and Molecular Biology Reviews, 64(3), 461-488. DOI: 10.1128/MMBR.64.3.461-488.2000

Margalith, P. \& Meydav S. (1968). Some observations on the carotenogenesis in the yeast Rhodotorula mucilaginosa. Phytochemistry, 7(5), 765-768. DOI: 10.1016/S00319422(00)84829-3

Margesin, R. \& Miteva, V. (2011). Diversity and ecology of psychrophilic microorganisms. Research in Microbiology, 162(3), 346-361. DOI: 10.1016/j.resmic.2010.12.004

Marova, I., Carnecka, M., Halienova, A., Certik, M., Dvorakova, T. \& Haronikova, A. (2012). Use of several waste substrates for carotenoid-rich yeast biomass production. Journal of Environmental Management, 95, S338-S342. DOI: 10.1016/j.jenvman.2011.06.018

Martelli, H. \& M. da Silva, I. (1993). [35] $\beta$-carotene synthesis in Rhodotorula. Methods in Enzymology, 214, 386-390. DOI: 10.1016/0076-6879(93)14082-T

Maza, D., Viñarta, S., Su, Y., Guillamón, J. \& Aybar, M. (2020). Growth and lipid production of Rhodotorula glutinis R4, in comparison to other oleaginous yeasts. Journal of Biotechnology, 310, 21-31. DOI: 10.1016/j. jbiotec.2020.01.012

Meng, X., Yang, J., Xu, X., Zhang, L., Nie, Q. \& Xian, M. (2009). Biodiesel production from oleaginous microorganisms. Renewable Energy, 34(1), 1-5. DOI: 10.1016/j.renene.2008.04.014

Merdinger, E. \& Devine, E. (1965). Lipids of Debaryomyces hansenii. Journal of Bacteriology, 89(6), 1488-1493. Retrieved from https://jb.asm.org/content/89/6/1488. long

Morano, K., Grant, C. \& Moye-Rowley, W. (2012). The Response to Heat Shock and Oxidative Stress in Saccharomyces cerevisiae. Genetics, 190(4), 1157-1195. DOI: 10.1534/genetics.111.128033

Morita, R. (1975). Psychrophilic bacteria. Bacteriological Reviews, 39(2), 144-167. Retrieved from https://www. ncbi.nlm.nih.gov/pmc/articles/PMC413900/

Nakayama, T., Mackinney, G. \& Phaff, H. (1954). Carotenoids in asporogenous yeasts. Antonie Van Leeuwenhoek, 20(1), 217-228. DOI: $10.1007 / \mathrm{bf0} 2543724$

Nam, H., Cho, S. \& Rhee, J. (1988). High-performance liquid chromatographic analysis of major carotenoids from Rhodotorula glutinis. Journal of Chromatography A, 448, 445-447. DOI: 10.1016/S0021-9673(01)84610-0

Nasrabadi, M. \& Razavi, S. (2011). Optimization of $\beta$-carotene production by a mutant of the lactose-positive yeast Rhodotorula acheniorum from whey ultrafiltrate. Food Science and Biotechnology, 20(2), 445-454. DOI: 10.1007/s10068-011-0062-1

Nielsen, J. (2009). Systems biology of lipid metabolism: From yeast to human. FEBS Letters, 583(24), 3905-3913. DOI: 10.1016/j.febslet.2009.10.054

Pan, J. \& Rhee, J. (1986). Biomass yields and energetic yields of oleaginous yeasts in batch culture. Biotechnology and Bioengineering, 28(1), 112-114. DOI: 10.1002/ bit.260280117

Papanikolaou, S. \& Aggelis, G. (2002). Lipid production by Yarrowia lipolytica growing on industrial glycerol in a single-stage continuous culture. Bioresource Technology, 82(1), 43-49. DOI: 10.1016/s0960-8524(01)00149-3

Papanikolaou, S. \& Aggelis, G. (2011). Lipids of oleaginous yeasts. Part I: Biochemistry of single cell oil production. European Journal of Lipid Science and Technology, 113(8), 1031-1051. DOI: 10.1002/ejlt.201100014

Papanikolaou, S., Chevalot, I., Komaitis, M., Aggelis, G. \& Marc, I. (2001). Kinetic profile of the cellular lipid composition in an oleaginous Yarrowia lipolytica capable of producing a cocoa-butter substitute from industrial fats. Antonie Van Leeuwenhoek, 80(3/4), 215-224. DOI: 10.1023/a:1013083211405

Papanikolaou, S., Muniglia, L., Chevalot, I., Aggelis, G. \& Marc, I. (2003). Accumulation of a Cocoa-ButterLike Lipid by Yarrowia lipolytica Cultivated on AgroIndustrial Residues. Current Microbiology, 46(2), 124130. DOI: 10.1007/s00284-002-3833-3

Perrier, V., Dubreucq, E. \& Galzy, P. (1995). Fatty acid and carotenoid composition of Rhodotorula strains. Archives of Microbiology, 164(3), 173-179. DOI: 10.1007/ bf02529968

Péter, G., Takashima, M. \& Čadež, N. (2017). Yeast Habitats: Different but Global. In: Buzzini P., Lachance MA., Yurkov A. (eds) Yeasts in Natural Ecosystems: Ecology, 39-71. DOI: 10.1007/978-3-319-61575-2 2

Peterson, W. J., Bell, T. A., Etchells, J. L. \& Smart, W.W. Jr. (1954) A procedure for demonstrating the presence of carotenoid pigments in yeasts. Journal of Bacteriology, 67(6), 708-713. Retrieve from: https://www.ncbi.nlm.nih. gov/pmc/articles/PMC357309/pdf/jbacter00555-0108. pdf

Peterson, W. J., Evans, W. R., Lecce, E., Bell, T. A. \& Etchells, J. L. (1958). Quantitative determination of the carotenoids in yeasts of the genus Rhodotorula. Journal of Bacteriology, 75(5), 586. Retrieved from https:// www.ncbi.nlm.nih.gov/pmc/articles/PMC290114/pdf/ jbacter00512-0111.pdf

Petrik, S., Marova, I., Haronikova, A., Kostovova, I. \& Breierova, E. (2013). Production of biomass, carotenoid and other lipid metabolites by several red yeast strains cultivated on waste glycerol from biofuel production a comparative screening study. Annals of Microbiology, 63(4), 1537-1551. DOI: 10.1007/s13213-013-0617-x

Poli, J. S., Rosa, P. D., Senter, L., Mendes, S. D. C., RamirezCastrillon, M., Vainstein, M. H. \& Valente, P. (2013). Fatty acid methyl esters produced by oleaginous yeast Yarrowia lipolytica QU21: an alternative for vegetable oils. Revista Brasileira de Biociências, 11, 203-208. Available at http://www.ufrgs.br/seerbio/ojs/index.php/ $\mathrm{rbb} /$ article/view/2524 
Pomraning, K., Kim, Y., Nicora, C., Chu, R., Bredeweg, E., Purvine, S., Hu, D., Metz, T.O. \& Baker, S. E. (2016). Multi-omics analysis reveals regulators of the response to nitrogen limitation in Yarrowia lipolytica. BMC Genomics, 17(1). DOI: 10.1186/s12864-016-2471-2

Raspor, P. \& Zupan, J. (2006). Yeasts in Extreme Environments. In: Péter, G. \& Rosa, C. (eds) Biodiversity and Ecophysiology of Yeasts. The Yeast Handbook, 371417. DOI: $10.1007 / 3-540-30985-315$

Ratledge, C. (2008). Microbial Lipids. In: Rehm, H.-J. \& Reed, G. (eds). Biotechnology: Products of Secondary Metabolism, Volume 7, Second Edition, 133-197. DOI: 10.1002/9783527620890.ch4

Reis-Mansur, M. C. P. P., Cardoso-Rurr, J. S., Abreu Silva, J. V. M., Rodrigues de Souza, G., da Silva Cardoso, V., Passos Mansoldo, F. R., Pinheiro, Y., Schultz, J., Lopez Balottin, L. B., Ribeiro da Silva, A. J., Lage, C., Pereira dos Santos, E., Soares Rosado, A. \& Vermelho, A. B. (2019). Carotenoids from UV-resistant Antarctic Microbacterium sp. LEMMJ01. Scientific Reports, 9(9554), 1 - 14. DOI: 10.1038/s41598-019-45840-6

Rilfors, L. \& Lindblom, G. (2002). Regulation of lipid composition in biological membranes-biophysical studies of lipids and lipid synthesizing enzymes. Colloids and Surfaces B: Biointerfaces, 26(1-2), 112-124. DOI: 10.1016/s0927-7765(01)00310-1

Romero-Aguilar, L., Pardo, J., Lomelí, M., Bocardo, O., Juárez Oropeza, M. \& Guerra Sánchez, G. (2017). Lipid droplets accumulation and other biochemical changes induced in the fungal pathogen Ustilago maydis under nitrogen-starvation. Archives of Microbiology, 199(8), 1195-1209. DOI: 10.1007/s00203-017-1388-8

Rossi, M., Buzzini, P., Cordisco, L., Amaretti, A., Sala, M., Raimondi, S., Ponzoni, C., Pagnoni U. M. \& Matteuzzi, D. (2009). Growth, lipid accumulation, and fatty acid composition in obligate psychrophilic, facultative psychrophilic, and mesophilic yeasts. FEMS Microbiology Ecology, 69(3), 363-372. DOI: 10.1111/j.1574-6941.2009.00727.x

Sakaki, H., Nakanishi, T., Komemushi, S., Namikawa, K. \& Miki, W. (2001). Torularhodin as a Potent Scavenger against Peroxyl Radicals Isolated from a Soil Yeast, Rhodotorula glutinis. Journal of Clinical Biochemistry and Nutrition, 30, 1-10. DOI: 10.3164/jcbn.30.1

Schroeder, W. \& Johnson, E. (1995a). Carotenoids protect Phaffia rhodozyma against singlet oxygen damage. Journal of Industrial Microbiology, 14(6), 502-507. DOI: 10.1007/bf01573965

Schroeder, W. \& Johnson, E. (1995b). Singlet Oxygen and Peroxyl Radicals Regulate Carotenoid Biosynthesis in Phaffia rhodozyma. Journal of Biological Chemistry, 270(31), 18374-18379. DOI: 10.1074/jbc.270.31.18374

Shi, K., Gao, Z., Shi, T., Song, P., Ren, L., Huang, H. \& Ji, X. (2017). Reactive Oxygen Species-Mediated Cellular
Stress Response and Lipid Accumulation in Oleaginous Microorganisms: The State of the Art and Future Perspectives. Frontiers in Microbiology, 8: 793. DOI: 10.3389/fmicb.2017.00793

Shivaji, S. \& Prasad, G. (2009). Antarctic Yeasts: Biodiversity and Potential Applications. In: Satyanarayana, T. \& Kunzem G. (eds.) Yeast Biotechnology: Diversity and Applications, 3-18. DOI: 10.1007/978-1-4020-8292-4_1

Simpson, K., Nakayama, T. \& Chichester, C. (1964). Biosynthesis of yeast carotenoids. Journal of Bacteriology, 88(6), 1688-1694. Retrieved from https:// jb.asm.org/content/88/6/1688

Sitepu, I., Garay, L., Sestric, R., Levin, D., Block, D., German, J. \& Boundy-Mills, K. (2014). Oleaginous yeasts for biodiesel: Current and future trends in biology and production. Biotechnology Advances, 32(7), 1336-1360. DOI: 10.1016/j.biotechadv.2014.08.003

Starmer, W. \& Lachance, M. (2011). Yeast Ecology. Chapter 6. In: Kurtzman, C. P., Fell, J. W. \& Boekhout, T. The Yeasts (Fifth Edition), 65-83. DOI: 10.1016/B978-0-44452149-1.00006-9

Taccari, M., Canonico, L., Comitini, F., Mannazzu, I. \& Ciani, M. (2012). Screening of yeasts for growth on crude glycerol and optimization of biomass production. Bioresource Technology, 110, 488-495. DOI: 10.1016/j. biortech.2012.01.109

Tang, W., Wang, Y., Zhang, J., Cai, Y. \& He, Z. (2019). Biosynthetic Pathway of Carotenoids in Rhodotorula and Strategies for Enhanced Their Production. Journal of Microbiology and Biotechnology, 29(4), 507-517. DOI: 10.4014/jmb.1801.01022

Tang, X., Lee, J. \& Chen, W. (2015). Engineering the fatty acid metabolic pathway in Saccharomyces cerevisiae for advanced biofuel production. Metabolic Engineering Communications, 2, 58-66. DOI: 10.1016/j. meteno.2015.06.005

Taskin, M., Sisman, T., Erdal, S. \& Kurbanoglu, E. (2011). Use of waste chicken feathers as peptone for production of carotenoids in submerged culture of Rhodotorula glutinis MT-5. European Food Research and Technology, 233(4), 657-665. DOI: 10.1007/s00217-011-1561-2

Tehlivets, O., Scheuringer, K. \& Kohlwein, S. (2007). Fatty acid synthesis and elongation in yeast. Biochimica et Biophysica Acta (BBA) - Molecular and Cell Biology of Lipids, 1771(3), 255-270. DOI: 10.1016/j. bbalip.2006.07.004

Tsuji, M. (2016). Cold-stress responses in the Antarctic basidiomycetous yeast Mrakia blollopis. Royal Society Open Science 3(7), 160116. DOI: 10.1098/rsos.160106

Turchetti, B., Marconi, G., Sannino, C., Buzzini, P. \& Albertini, E. (2020). DNA Methylation Changes Induced by Cold in Psychrophilic and Psychrotolerant Naganishia Yeast Species. Microorganisms, 8(2), 296. DOI: 10.3390/ microorganisms 8020296 
Van Uden, N. (1985). Temperature Profiles of Yeasts. Advances in Microbial Physiology, Vol. 25, 195-251. DOI: 10.1016/s0065-2911(08)60293-3

Villarreal, P., Carrasco, M., Barahona, S., Alcaíno, J., Cifuentes, V. \& Baeza, M. (2016). Tolerance to Ultraviolet Radiation of Psychrotolerant Yeasts and Analysis of Their Carotenoid, Mycosporine, and Ergosterol Content. Current Microbiology, 72(1), 94-101. DOI: 10.1007/ s00284-015-0928-1

Villarreal, P., Carrasco, M., Barahona, S., Alcaíno, J., Cifuentes, V. \& Baeza, M. (2018). Antarctic yeasts: analysis of their freeze-thaw tolerance and production of antifreeze proteins, fatty acids and ergosterol. BMC Microbiology, 18, 66. DOI: 10.1186/s12866-018-1214-8

Villoutreix, J. (1960). Les caroténoïdes de Rhodotorula mucilaginosa étude de leur biosynthèse a l'aide de l'analyse de mutants et de l'emploi d'un inhibiteur de la caroténogénèse. Biochimica et Biophysica Acta, 40, 442457. DOI: 10.1016/0006-3002(60)91385-8

Viñarta, S., Angelicola, M., Barros, J., Fernández, P., Mac Cormak, W., Aybar, M. \& de Figueroa, L. (2016). Oleaginous yeasts from Antarctica: Screening and preliminary approach on lipid accumulation. Journal of Basic Microbiology, 56(12), 1360-1368. DOI: 10.1002/ jobm.201600099

Viñarta, S., Angelicola, M. V., Van Nieuwenhove, C., Aybar, M. \& de Figueroa, L. (2020). Fatty Acids Profiles and Estimation of the Biodiesel Quality Parameters from Rhodotorula spp. From Antarctica. Biotechnology Letters, 42(5), 757-772. DOI: 10.1007/s10529-020-02796-2

Wang, S. L., Liu, W., Wang, H. \& Lv, C. (2012). Ultra HighPressure and Ion Implantation Combined Mutagenesis to Improve the Production of $\beta$-Carotene from Red Yeast. Advanced Materials Research, 554-556, 1165-1169. DOI: 10.4028/www.scientific.net/amr.554-556.1165
Wang, S. L., Sha, X. \& Wang, H. X. (2016). Improving yield of beta carotene in red yeast by using fermentation promoter. Food and Nutrition in China. 2016 issue 5, 58-60. Retrieved from http://caod.oriprobe.com/ articles/48823400/Improving_Yield_of_Beta_ Carotene_in_Red_Yeast_by_Using_Fermentation_ Pr.htm

Wang, S. L., Sun, J., Han, B. \& Wu, X. (2007). Optimization of $\beta$-Carotene Production by Rhodotorula glutinis Using High Hydrostatic Pressure and Response Surface Methodology. Journal of Food Science, 72(8), M325-M329. DOI: 10.1111/j.1750-3841.2007.00495.x

Wilhelm, S. \& Helmut, S. (2012). $\beta$-Carotene and other carotenoids in protection from sunlight, The American Journal of Clinical Nutrition, 96(5), 1179S-1184S. DOI: 10.3945/ajcn.112.034819

Wiebe, M., Koivuranta, K., Penttilä, M. \& Ruohonen, L. (2012). Lipid production in batch and fed-batch cultures of Rhodosporidium toruloides from 5 and 6 carbon carbohydrates. BMC Biotechnology, 12, 26. DOI: 10.1186/1472-6750-12-26

Wolf, K., Breunig, K. D. \& Barth, G. (2003). Non-Conventional Yeasts in Genetics, Biochemistry and Biotechnology. Practical Protocols. SpringerLink.

Xie, D. (2017). Integrating Cellular and Bioprocess Engineering in the Non-Conventional Yeast Yarrowia lipolytica for Biodiesel Production: A Review. Frontiers In Bioengineering and Biotechnology, 5, 65. DOI: 10.3389/fbioe.2017.00065

Zhao, X., Kong, X., Hua, Y., Feng, B. \& Zhao, Z. (2008). Medium optimization for lipid production through cofermentation of glucose and xylose by the oleaginous yeast Lipomyces starkeyi. European Journal of Lipid Science and Technology, 110(5), 405-412. DOI: 10.1002/ ejlt.200700224 